\title{
Evaluation of Cell Toxicity and Surface Properties of Surface Modified Ti and Ti Alloys
}

\author{
Oh-Seong Kwon ${ }^{1, * 1}$, Hyeoung-Ho Park ${ }^{1, * 2}$, Oh-Yon Lee ${ }^{1}$ and Min-Ho Lee ${ }^{2}$ \\ ${ }^{1}$ School of Advanced Materials Engineering, Chonbuk National University, Jeonju 561-756, South Korea \\ ${ }^{2}$ Department of Dental Biomaterials, School of Dentistry, Chonbuk National University, Jeonju 561-756, South Korea
}

\begin{abstract}
This study was performed to investigate the surface properties and cell toxicity of the anodized and hydrothermally treated $\mathrm{Ti}$, Ti-6Al-4V alloy and Ti-6Al-7Nb alloy. Bioactivity was evaluated from the surface activation layers formed on the surface of specimens in simulated body fluid (SBF) for a period of 30 days. Cell toxicity was evaluated based on the optical density of the survival cell. The porous oxide films were formed on all of the specimens by anodic oxidation. The oxide films of Ti were composed of strong anatase peaks without rutile peaks, Ti-6Al$4 \mathrm{~V}$ alloy was composed of weak anatase peaks and weak rutile peaks and Ti-6Al-7Nb alloy was composed of strong anatase peaks and weak rutile peaks. The oxide films of all of the specimens exhibited an increase in the intensity of anatase peaks after hydrothermal treatment. The surface activation layers were formed only on the oxide films of Ti-6Al-7Nb alloy, also this alloy presented a significantly higher optical density than Ti and Ti-6Al-4V alloy on the MTT assay for cell toxicity evaluation. [doi:10.2320/matertrans.47.2033]
\end{abstract}

(Received April 13, 2006; Accepted June 12, 2006; Published August 15, 2006)

Keywords: biomaterial, anodizing, hydrothermal treatment, cell toxicity

\section{Introduction}

$\mathrm{Ti}$ and $\mathrm{Ti}$ alloys present high specific strength and excellent heat and corrosion resistance. These can be widely applied to the field of machinery, electronics, aircraft, and military equipment. In particular, these can be used as an implant material in the field of orthopedics and dentistry due to the excellent biocompatibility of the surface characteristics of $\mathrm{Ti}$ and $\mathrm{Ti}$ alloys. The superior corrosion resistance and biocompatibility of $\mathrm{Ti}$ and $\mathrm{Ti}$ alloys are due to a dense $\mathrm{TiO}_{2}$ passive layer, which is rapidly formed on their surface. The oxide film naturally generated in the air, mainly forms a chemically and thermodynamically stable $\mathrm{TiO}_{2}$ rutile structure which presents no inflammation or toxic reactions because it has low solubility in simulated body fluid (SBF); however, because the $\mathrm{TiO}_{2}$ rutile structure is inactive due to its stability in an organism, approximately 6 months is required for osteointegration to occur. Studies on the bioactivity of surface layers, formed by various surface treatment methods, have been conducted to reduce the medical treatment period and to improve the osteosynthesis.

Among these surface treatment methods a plasma coating method applies plasma using bioactive hydroxyapatite (HA) powder, however because a large part of the crystal phase will be transformed into an amorphous shape or unstable structure during the melting injection with an ultra high temperature exceeding $10,000^{\circ} \mathrm{C}$; there are some reports on problems occurring after implanting, such as dissolution of the surface layer, cracks in the interface of base metal and surface layers and separations of the deposited material. ${ }^{1,2)}$ Studies on the surface treatment methods for surface layer, which presents an effect of HA coating and strong resistance against a certain exfoliation, have been actively conducted to

\footnotetext{
${ }^{* 1}$ Graduate Student, Chonbuk National University. Present Address: Research Facility Center, College of Engineering, Chonbuk National University, Jeonju 561-756, South Korea

${ }^{* 2}$ Graduate Student, Chonbuk National University. Present Address:

Jeonju City Development Institute, Jeonju 561-700, South Korea
}

solve these problems. An electrolyte solution treatment method with alkali metal ion, ${ }^{3)}$ a calcium ion injection method, which injects calcium on the surface of implant, using an ion beam ${ }^{4)}$ and an electrochemical treatment method in $\mathrm{SBF}{ }^{5)}$ have been investigated in many studies. Anodic oxidation is a type of electrochemical surface treatment method, which is able to form porous oxide films and has various characteristics according to the type of electrolyte solution, regardless of the type of specimens. The characteristics of oxide film can be altered by controlling certain experimental conditions such as electrolyte types, electrolyte concentration, temperature of electrolyte solution and voltage and current density; in addition the characteristics of osteosynthesis can be improved using a partial crystallization which crystallizes calcium and phosphorus existing in an oxide film as a type of ion, through an additional hydrothermal treatment.

The most stable oxide among $\mathrm{Ti}$ oxides is $\mathrm{TiO}_{2}$, which due to very high negative Gibbs free energy presents a very stable state in terms of the thermodynamic process. Ti is not an appropriate material for application to high stress conditions, such as an implant material, due to an inadequate level of strength. ${ }^{6)}$ In recent years a new type of alloy, such as Ti-6Al$7 \mathrm{Nb}$ was considered. This alloy which is a type of $\alpha+\beta$ that utilizes a biocompatible niobium avoids the problematic level of vanadium toxicity presents in Ti-6Al-4V alloy. ${ }^{7,8)}$ It was reported that the $\mathrm{Ti}-6 \mathrm{Al}-7 \mathrm{Nb}$ alloy presents similar levels of mechanical strength, abrasion resistance and corrosion resistance as that of the Ti-6Al-4V alloy. ${ }^{9}$ )

This study investigated the surface activation of $\mathrm{Ti}$, Ti$6 \mathrm{Al}-4 \mathrm{~V}$ alloy and $\mathrm{Ti}-6 \mathrm{Al}-7 \mathrm{Nb}$ alloy, which are used as implant materials, treated by anodic oxidation and hydrothermal treatment in order to improve the biocompatibility and osteosynthesis of the alloys; in addition the cell toxicity for each material was evaluated by MTT assay. 
Table 1 Chemical composition of Ti and Ti alloys (mass).

\begin{tabular}{lccccccccc}
\hline Specimens & $\mathrm{H}$ & $\mathrm{N}$ & $\mathrm{O}$ & $\mathrm{C}$ & $\mathrm{Al}$ & $\mathrm{V}$ & $\mathrm{Nb}$ & $\mathrm{Fe}$ & $\mathrm{Ti}$ \\
\hline Ti & 0.001 & 0.01 & 0.07 & - & - & - & - & 0.04 & Bal. \\
Ti-6Al-4V & 0.004 & 0.003 & 0.147 & 0.005 & 6.23 & 4.12 & - & 0.189 & Bal. \\
Ti-6Al-7Nb & 0.003 & 0.005 & 0.124 & 0.004 & 6.21 & - & 7.15 & 0.176 & Bal. \\
\hline
\end{tabular}

\section{Materials and Methods}

\subsection{Materials}

The specimens used in this study were prepared using the materials noted in Table 1 and the specimens were ground using sandpaper in the range of \#220-\#1,000. An ultrasonic cleaning process was applied to the specimens using distilled water, alcohol and acetone for 5 minutes, and then the specimens were stored in a dry place at $50^{\circ} \mathrm{C}$ for a period of 24 hours. The electrolyte solution was prepared by dissolving $0.02 \mathrm{~mol} / \mathrm{L}$ of DL- $\alpha$-glycerophosphate disodium salt hydrate (DL- $\alpha$-GP) and $0.2 \mathrm{~mol} / \mathrm{L}$ of calcium acetate (CA) in distilled water. The spark discharge anodic oxidation was operated using a constant current mode up to the configured voltage and a DC regulated power supply (Kwangduck FA, Korea), which could be automatically changed from a constant current mode to a constant voltage mode; such a voltage was applied after the constant current mode. The specimen and platinum plate were connected to both anode and cathode sides respectively using the $\mathrm{DC}$ regulated power source and were treated with $30 \mathrm{~A} / \mathrm{m}^{2}$ and $300 \mathrm{~V}$. The hydrothermal treatment was performed at $300^{\circ} \mathrm{C}$ and $8.8 \mathrm{MPa}$ of steam pressure in a high temperature and pressurized autoclave (ISA-BC-0060-SS-05-SYS, Ilshin Autoclave, Korea) filled with distilled water.

\subsection{Surface analysis}

Morphological structures of the coated layer for the various conditions were measured using a scanning electron microscope (SM-350, TOPCON, Japan). In addition, an Xray diffraction (D/MAX-2500, Rigaku, Japan) with Cu target was used to analyze the crystal structure of the element in the oxide films using a powder measuring method. In particular a thin film measuring method, which was set at a low angle of 3 degrees, was used to examine changes in the surface layer. The chemical composition and electron structure of the surface were analyzed using an X-ray photoelectron spectroscope (ESCALAB250, VG Scientific Ltd., England) with an $\mathrm{Al}$ target.

\subsection{Soaking in simulated body fluid (SBF)}

The SBF, which consisted of a similar composition as human serum with corresponding $\mathrm{pH}$ value and ion concentration, was used to evaluate the biocompatibility of the specimens. The specimens were treated at $121^{\circ} \mathrm{C}$ for 20 minutes using a high-pressure sterilization process. The specimens were then transfered to an incubator with 5\% of $\mathrm{CO}_{2}$ for a period of 30 days at a constant temperature of $36.5^{\circ} \mathrm{C}$. During the immersion in the incubator, the solution was replaced every two days in order to prevent its concentration changing. The SBF was produced by adding $0.185 \mathrm{~g} / \mathrm{L}$ of calcium chloride dihydrate, $0.09767 \mathrm{~g} / \mathrm{L}$ of magnesium sulfate and $0.350 \mathrm{~g} / \mathrm{L}$ of sodium hydrogen carbonate into the Hanks' balanced solution (H2387, Sigma Chemical Co, USA). The pH of SBF was controlled at 7.4.

\subsection{Cell culture}

Specimens used to evaluate cell toxicity were prepared using the high-pressure sterilization process at $121^{\circ} \mathrm{C}$ for 20 minutes using untreated specimen, anodic oxidation treated specimens and thermally treated specimens. In addition a ROS $17 / 2.8$ cell, which is a type of rat osteosarcoma cell line, was used as a base cell and $1 \%$ antibiotic-antimycotic mixture (Sigma, St. Louis, MO) and DMEM (Gibco Co., USA) with $10 \%$ PBS were used as a cultivation solution. This solution was cultivated in an incubator which was maintained in $5 \% \mathrm{CO}_{2}$ at $36.5^{\circ} \mathrm{C}$. The prepared specimens were set in 12 well plates and cells composed of $1 \times 10^{6}$ cells/well for the specimens. In addition $2 \mathrm{~mL}$ of cultivation solution was added into each well and the cells were cultivated in the well plate for 4 days.

\subsection{MTT assay}

Cell toxicity was evaluated by measuring 3-(4.5-dimethylthiazol-2-yl)-2.5-diphenyl tetrazolium bromide (MTT) ${ }^{10)}$ MTT can transform tetrazolium salt to formazan through an internal cell metabolism in which the activity of the cell metabolism can be measured by monitoring the change using an ELISA leader. The measurement using an ELISA leader (Molecular Divices, Sunnyvale, CA94089, USA) was applied by inserting dimethylsalfoxide after cultivating the MTT( $100 \mu \mathrm{g} / 0.1 \mathrm{~mL}$ PBS $)$ solution for 1 hour. The MTT solution was inserted by $100 \mu \mathrm{g}$ for each well cultivated during the 4 day period. The test was repeated three times for each group using the wavelength of $570 \mathrm{~nm}$.

\section{Results}

Figure 1 presents the results of the SEM and XRD of the oxide films of Ti, Ti-6Al-4V alloy and Ti-6Al-7Nb alloy that
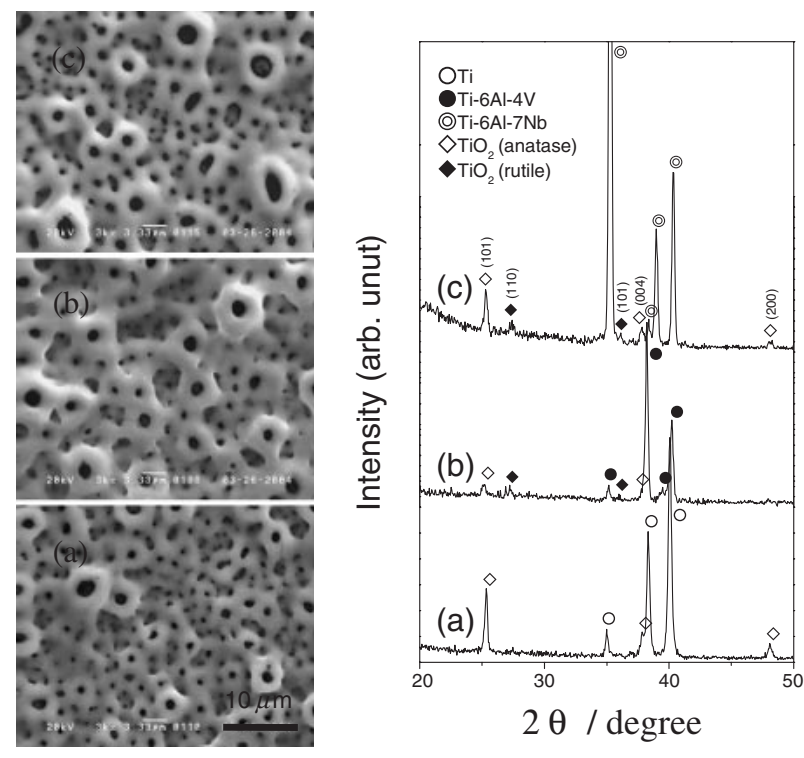

Fig. 1 SEM images and XRD patterns of anodic oxide films: (a) Ti, (b) Ti6Al-4V alloy, and (c) Ti-6Al-7Nb alloy. 

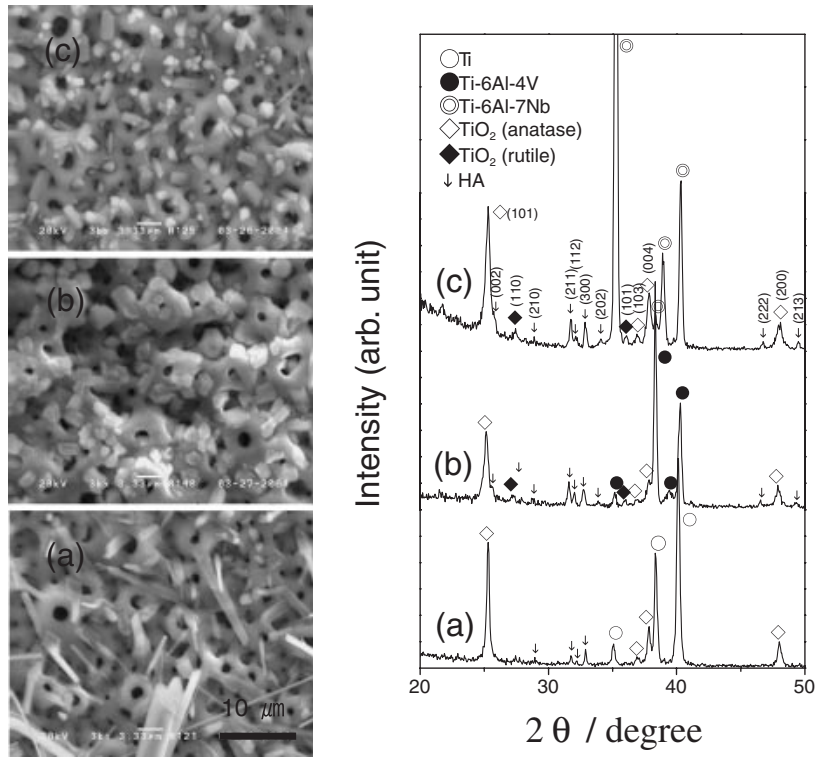

$2 \theta /$ degree

Fig. 2 SEM images and XRD patterns of anodic oxide films after hydrothermal treatment at $300^{\circ} \mathrm{C}$ for 2 hours: (a) Ti, (b) Ti-6Al-4V alloy, and (c) Ti-6Al-7Nb alloy.

were treated using an anodic oxidation method under the condition of $300 \mathrm{~V}$ and $30 \mathrm{~mA} / \mathrm{cm}^{2}$. Oxide films present hundreds of $\mathrm{nm} \sim 3 \mu \mathrm{m}$ of pores on the oxide films for each specimen and the oxide films of Ti present a smaller porous size than that of the Ti-6Al-4V alloy and Ti-6Al-7Nb alloy. A $\mathrm{TiO}_{2}$ anatase peak was detected in the specimen applied to the XRD measurement and the peak intensity of Ti-6Al-4V alloy was weaker than that of the Ti and Ti-6Al-7Nb alloy. The $\mathrm{TiO}_{2}$ rutile peak was detected in Ti-6Al-4V alloy and Ti$6 \mathrm{Al}-7 \mathrm{Nb}$ alloy but was not detected in the oxide films of Ti.

Figure 2 presents the results of the SEM and XRD of the oxide films, which were treated using a hydrothermal treatment at $300^{\circ} \mathrm{C}$ for 2 hours after applying an anodic oxidation process. Various types of HA for the specimen were formed on the surface of the oxide films. A similar type of apatite was formed on the oxidized surface of Ti-6Al-4V alloy and $\mathrm{Ti}-6 \mathrm{Al}-7 \mathrm{Nb}$ alloy, however the precipitates of $\mathrm{Ti}-$ $6 \mathrm{Al}-7 \mathrm{Nb}$ alloy exhibited a finer shape. Irregular shapes of $\mathrm{HA}$, such as that of a needle or angular column, were formed on the oxidized surface of Ti. Crystal peaks of the newly produced HA were detected during XRD analysis for each hydrothermally treated material and an increase in the intensity of $\mathrm{TiO}_{2}$ anatase peaks was also observed.

Figure 3 presents the results of the SEM and XRD of the specimens, which were treated using a hydrothermal treatment at $300^{\circ} \mathrm{C}$ for 2 hours after applying an anodic oxidation process and were subsequently immersed in SBF for 30 days. A new surface layer, which had an amorphous property that differed from the $\mathrm{Ti}$ and the Ti-6Al-4V alloy was formed on the surface of the Ti-6Al-7Nb alloy. From the XRD analysis at the surface layer of the Ti-6Al-7Nb alloy, a superimposed peak of amorphous phase and HA crystal were detected in the vicinity of $31-33^{\circ}$.

Figure 4 presents the results of XPS for the surface of the Ti-6Al-7Nb alloy, which had an amorphous type of surface activation layer, observed after immersing a hydrothermally
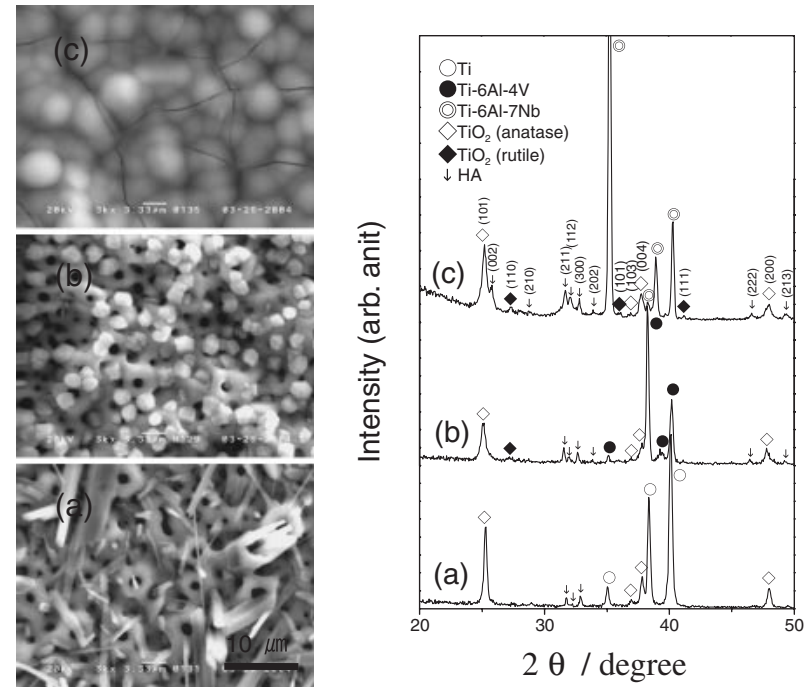

Fig. 3 SEM images and XRD patterns of hydrothermally treated anodic oxide films after immersion in SBF for 30 days: (a) Ti, (b) Ti-6Al-4V alloy, and (c) Ti-6Al-7Nb alloy.
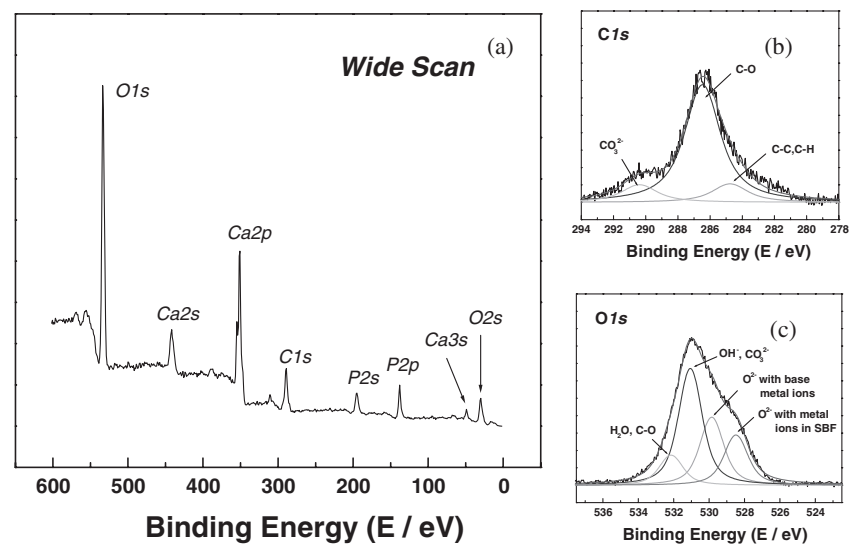

Fig. 4 XPS spectra of the hydrothermally treated anodic oxide films of Ti6Al-7Nb alloy after immersion in SBF for 30 days: (a) wide scan, (b) C $1 s$ spectrum, and (c) $\mathrm{O} 1 s$ spectrum.

treated specimen in the SBF for 30 days. The peaks, which presented binding energies of $\mathrm{C} 1 s, \mathrm{O} 1 s, \mathrm{O} 2 s, \mathrm{Ca} 2 p$, $\mathrm{Ca} 2 s, \mathrm{Ca} 3 s, \mathrm{P} 2 s$ and $\mathrm{P} 2 p$ were observed on the surface layer in the wide scan, however there were no peaks of the matrix. From the results of a narrow scan about a binding energy of $\mathrm{O} 1 s$ and $\mathrm{C} 1 s$, the binding energy of $\mathrm{O} 1 s$ spectrum which consisted of the $\mathrm{O}^{2-}$ bond (metal ion in the $\mathrm{SBF}$ ), the $\mathrm{O}^{2-}$ bond (metal ions of oxide layer), the $\mathrm{OH}^{-}$and $\mathrm{CO}_{3}{ }^{2-}$ bond and the $\mathrm{H}_{2} \mathrm{O}, \mathrm{C}-\mathrm{O}$ bond presented 528.82, $530.04,531.34$ and $532.42 \mathrm{eV}$ respectively. The binding energies of $\mathrm{C} 1 \mathrm{~s}$ spectrum, which consisted of the $\mathrm{CO}_{3}{ }^{2-}$ bond, C-O bond, C-C and C-H bond presented 290.97, 286.94 and $285.00 \mathrm{eV}$ respectively.

Figure 5 presents the results of the XRD, which was used as a thin film measuring method, for each surface treatment process for the Ti-6Al-7Nb alloy that formed a surface activation layer. The $\mathrm{TiO}_{2}$ anatase and $\mathrm{TiO}_{2}$ rutile peak were measured in the oxide films. HA peaks were newly measured 


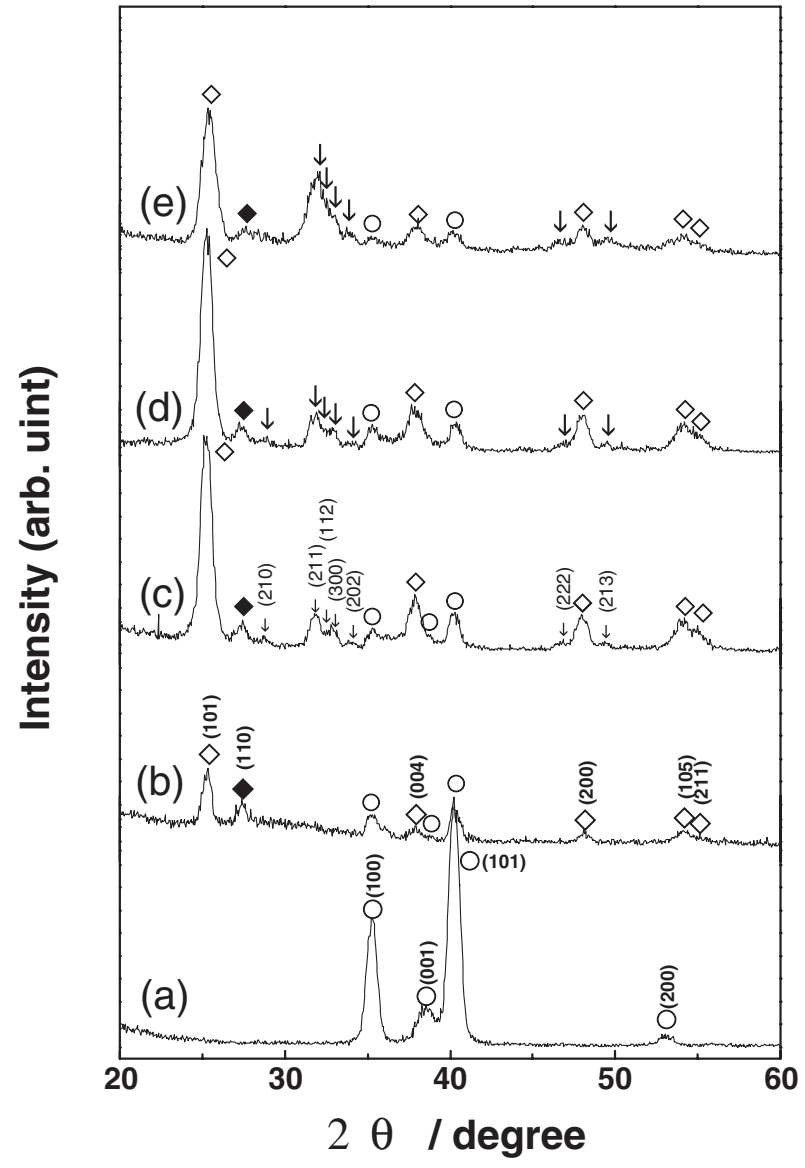

Fig. 5 XRD patterns of surface layer: (a) bulk Ti-6Al-7Nb alloy, (b) anodic oxide film, (c) hydrothermally treated anodic oxide film, (d) surface of (c) immerged in SBF for 10 days, and (e) surface of (c) immerged in $\mathrm{SBF}$ for 30 days ( $\bigcirc \mathrm{Ti}-6 \mathrm{Al}-7 \mathrm{Nb}, \diamond \mathrm{TiO}_{2}$ (anatase), $\diamond \mathrm{TiO}_{2}$ (rutile), and $\downarrow$ Hydroxyapatite).

in the hydrothermally treated surface. It was also evident that the $\mathrm{TiO}_{2}$ anatase peak intensity significantly increased in the hydrothermally treated surface. There were no changes in the peak of the oxide film, which was immersed in the SBF for 10 days, but the specimen immersed in the SBF for 30 days presented a superimposed peak which consisted of a HA crystal peak and an amorphous phase peak, in the vicinity of $31-33^{\circ}$.

Figure 6 presents the results of the evaluation of the cell toxicity by measuring the optical density using the MTT assay after cultivating for 4 days by applying the raw materials, anodized specimens and hydrothermally treated specimens. Ti specimens were not significantly affected during the treatment process, however the optical density increased after the anodic oxidation and hydrothermal treatment. The optical density of Ti-6Al-4V alloy increased due to the anodic oxidation but significantly decreased after applying a hydrothermal treatment. Ti- $6 \mathrm{Al}-7 \mathrm{Nb}$ alloy presented a significantly increased optical density over that of the untreated group after treating an anodic oxidation even though the optical density decreased after applying a hydrothermal treatment. The optical density of Ti-6Al-7Nb alloy for the raw materials, anodized specimens and hydrothermally treated specimens had significantly higher values than those of the Ti and Ti-6Al-4V alloy.

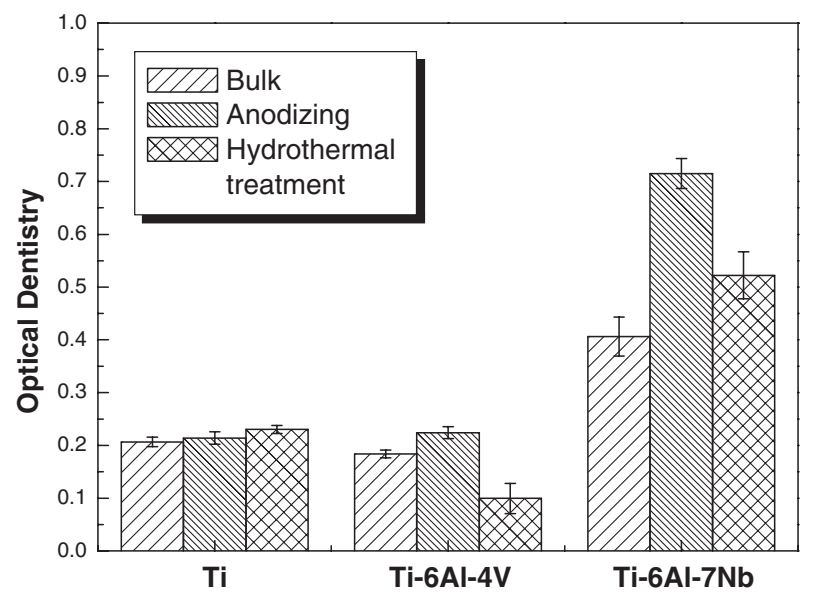

Fig. 6 Optical density measured after culture for 4 days at a wavelength of $570 \mathrm{~nm}$ by ELISA reader ( $n=5$ per group).

\section{Discussion}

The anodic oxidation method applied in this study formed the porous $\mathrm{TiO}_{2}$ films, which was produced by the spark discharge anodic oxidation. This method is a desirable means to improve the pace of surface activation and osteosynthesis when an implant is set in bone by absorbing $\mathrm{Ca}$ and $\mathrm{P}$, which exist in the electrolyte solution, to a porous oxidation surface layer. Regarding this surface treatment, Ishizawa et al. ${ }^{11)}$ reported that a thin and rough porous $\mathrm{TiO}_{2}$ layer, which absorbs $\mathrm{Ca}$ and $\mathrm{P}$, can produce an oxide film which has a bioactivity, when a surface layer was treated using the electrolyte solution including $\mathrm{Ca}$ and $\mathrm{P}$; also the ratio of $\mathrm{Ca} / \mathrm{P}$ of the oxide film, which was treated using an anodic oxidation in the electrolyte solution with $\beta$-glycerophosphate disodium salt hydrate $(\beta-\mathrm{GP})$ and CA presented a similar value as that of the HA; the cell compatibility presented satisfactory results.

This study produced porous oxide films, was a typical result of anodic oxidation, in the electrolyte solution that included both DL- $\alpha$-GP and CA electrolytes (Fig. 1); it is evident that these porous oxide films facilitate a faster surface activation compared to the untreated specimens because $\mathrm{Ca}$ and $\mathrm{P}$ were absorbed on the oxide films. Although $\mathrm{TiO}_{2}$ peaks were observed during XRD analysis, the $\mathrm{TiO}_{2}$ films mainly presented anatase and rutile structure and the $\mathrm{TiO}_{2}$ peaks presented different shapes for each specimen. In this study $\mathrm{Ti}$ presented a relatively strong anatase peak without any rutile peak, while the Ti-6Al-4V alloy presented weak anatase and rutile peak and the Ti-6Al-7Nb alloy presented strong anatase and weak rutile peaks (Fig. 1). In these different $\mathrm{TiO}_{2}$ structures for each specimen, the surface of the oxide films that had the anatase structure presented negative charge and the oxide film absorbed $\mathrm{Ca}$ ions in the SBF. In addition, $\mathrm{Ca}$ ions absorb $\mathrm{PO}_{4}$ ions which can produce apatite; ${ }^{12,13)}$ then the amorphous phosphoric calcium can be formed on the surface of the oxide films. In addition, the $\mathrm{TiO}_{2}$ rutile (101) crystal plane serves as a nucleus for growth of an apatite crystal that correlates to the apatite (002) crystal plane. ${ }^{14,15)}$ Considering the results of their studies, the different crystal structures of 
$\mathrm{TiO}_{2}$ oxide films in this study will play an important role in the activation of oxide films.

Various types of apatites were formed by the hydrothermal treatment on the surface of all materials and the XRD analysis presented a new apatite peak and significant increase in the anatase peak of $\mathrm{TiO}_{2}$ films, however there were no changes of intensity in the $\mathrm{TiO}_{2}$ rutile peak. This was due to the fact that the applied temperature of the hydrothermal treatment was $300^{\circ} \mathrm{C}$, the same as the $\mathrm{TiO}_{2}$ anatase forming temperature. The hytrothermally treated oxide films can induce a faster activation compared to the oxide films due to the significant increase in the $\mathrm{TiO}_{2}$ anatase phase and the formed HA crystal on the surface (Figure 2). For a hydrothermal treatment, Ishizawa and Ogino reported that the surface activation was unattainable in anodized oxide films because the activation energy presented a high level, and the achievement of surface activation is necessary to induce the formation of HA crystal by reacting $\mathrm{OH}^{-}$with $\mathrm{Ca}$ and $\mathrm{P}$, which exist as ions in anodized oxide films, under the high temperature and pressure. ${ }^{11)}$

The XRD analysis that was applied to the oxide films which showed the activation, presented a superimposed shape of the HA peak and an amorphous calcium phosphate peak, existed in the vicinity of $31-33^{\circ}$. This was due to the fact, that the specimen was covered by an activation layer, which mainly consisted of $\mathrm{Ca}$ and $\mathrm{P}$ (Fig. 3). From the results of XRD, which was used as a thin film measuring method for the surface of $\mathrm{Ti}-6 \mathrm{Al}-7 \mathrm{Nb}$ that presented the activation, it is evident that a surface activation layer was generally formed on the surface of the oxide films. In addition, the XPS analysis of the activation surface presented the binding energy of $\mathrm{C} 1 s, \mathrm{O} 1 s, \mathrm{O} 2 s, \mathrm{Ca} 2 p, \mathrm{Ca} 2 s, \mathrm{Ca} 3 s, \mathrm{P} 2 p$ and $\mathrm{P} 2 s$ without any peaks of the metal base on the surface. Moreover, The binding energy of $\mathrm{O} 1 s$ spectrum consisted of the $\mathrm{O}^{2-}$ bond (metal ions in the SBF) was newly measured in the surface activation layer.

Considering the activation mechanism described in the previous section, the surface activation of Ti-6Al-7Nb alloy can be facilitated by the large amount of $\mathrm{TiO}_{2}$ anatase phases that can cultivate negative charge on the surface, though the rutile structure showed higher negative charge than anatase structure, because of the fact that anatase structure was formed in a major portion of surface layer, and the $\mathrm{TiO}_{2}$ rutile phase, which may be a nucleus of the apatite. In particular, the surface activation can be promoted by the increase in the $\mathrm{TiO}_{2}$ anatase phase and the formation of $\mathrm{HA}$ due to the hydrothermal treatment. However, because no $\mathrm{TiO}_{2}$ rutile phase at the oxide films of $\mathrm{Ti}$ and the small amount of $\mathrm{TiO}_{2}$ anatase phase on the oxide films of Ti-6Al-4V alloy were unable to satisfy the necessary conditions for production of the surface activation layers; there were no activations during the immersion period of the SBF.

\section{Conclusions}

Although all materials that were anodized in the electrolyte solution containing $\mathrm{Ca}$ and $\mathrm{P}$ produced porous oxide films containing $\mathrm{Ca}$ and $\mathrm{P}$, only $\mathrm{Ti}-6 \mathrm{Al}-7 \mathrm{Nb}$ alloy formed activation layers on the surface of oxide films during the immersion period of the SBF. The surface activation of the oxide films of Ti-6Al-7Nb alloy was due to the existence of $\mathrm{TiO}_{2}$ rutile and the relatively large amount of $\mathrm{TiO}_{2}$ anatase phases, which performed the surface activation. The Ti-6Al$7 \mathrm{Nb}$ alloy generally presented a higher optical density in the evaluation of the toxicity before and after applying a surface treatment process compared to other materials. In addition, each material presented an increase in the optical density after an anodic oxidation process was applied. However, in the case of the Ti-6Al-4V alloy and Ti-6Al-7Nb alloy, the optical density decreased after a hydrothermal treatment was applied. In particular, Ti-6Al-4V alloy presented a significant decrease in optical density.

\section{Acknowledgement}

"This work was supported by the Regional Research Centers Program of the Korean Ministry of Education \& Human Resources Development through the Center for Healthcare Technology Development.”

\section{REFERENCES}

1) B. C. Wang, T. M. Lee, E. Chang and C. Y. Yang: J. Biomed. Mater. Res. 27 (1993) 1315-1327.

2) K. Hayashi, T. Inadome, T. Mashima and Y. Sugioka: J. Biomed. Mater. Res. 27 (1993) 557-563.

3) W. Q. Yan, T. Nakamura, M. Kobayashi, H. M. Kim and F. Mijaji: J. Biomed. Mater. Res. 37 (1996) 267-275.

4) T. Hanawa, H. Ukai, K. Murakami and K. Asaoka: Mater. Trans. JIM. 36 (1995) 438-444.

5) S. Ban, S. Maruno, A. Harada, M. Hattori, K. Narita and J. Hasegawa: Dent. Mater. J. 15 (1996) 31-38.

6) T. Hirata, T. Nakamura, F. Takashima, T. Maruyama, M. Taira and J. Takahashi: J. Oral Rehab. 28 (2001) 773-777.

7) K. Kuroiwa and Y. Igarashi: J. Jpn. Prosthodont Soc. 42 (1998) 547558.

8) D. Iijima, T. Toneyama, H. Doi, H. Hamanaka and N. Kurosaki: Biomaterials. 24 (2003) 1519-1524.

9) M. Long and H. J. Rack: Biomaterials. 19 (1998) 1621-1639.

10) T. Mossman: J. Immunol. Meth. 65 (1983) 55-63.

11) H. Ishizawa and M. Ogino: J. Biomed. Mater. Res. 29 (1995) 10711079.

12) H. Takadama, H. M. Kim, T. Kokubo and T. Nakamura: J. Biomed. Mater. Res. 55 (2001) 185-193.

13) H. Takadama, H. M. Kim, T. Kokubo and T. Nakamura: J. Biomed. Mater. Res. 57 (2001) 441-448.

14) P. J. Li, C. Ohtsuki, T. Kokubo, K. Nakanishi, N. Soga and K. De Groot: J. Biomed. Mater. Res. 28 (1994) 7-16.

15) M. C. Bryan: Nature. 260 (1976) 727-729. 